\title{
A REPRESENTAÇÃO DA MULHER NO DISCURSO RELIGIOSO
}

\author{
Caroline Helena dos Santos (G-UENP-IC) \\ Osnir Branco (G-UENP-IC) \\ Letícia Jovelina Storto (UENP) \\ Vanessa Hagemeyer BURGO (UFMS)
}

\section{RESUMO}

Este trabalho, que é fruto de uma pesquisa de iniciação científica, visa a analisar a representação da mulher e o papel do feminino no discurso religioso cristão, mais especificamente no discurso bíblico. Para tanto, recorre à Análise do Discurso de corrente francesa, justamente por considerar que essa teoria dá suporte para compreender a Formação Ideológica presente no discurso. O corpus de análise é formado pelos livros bíblicos de 1 Timóteo, Efésios e Tito. Por meio da análise, observou-se que a mulher tem papel marginalizado, submisso ao homem, que se em geral a mulher é retratada por meio de uma ideologia machista. Nos textos analisados, o objetivo é capturar a mulher que já é oprimida pela sociedade patriarcal e assujeitá-la ainda mais à opressão, que, nesse caso, vem de um poder ainda mais superior (poder de Deus), determinando a ela papéis secundários, de inferioridade, de submissão. Ela é representada como frágil, dependente e, por vezes, pecadora.

Palavras-Chave: Discurso religioso. Representação. Mulher. Ideologia.

\section{CONSIDERAÇÕES INICIAIS}

Este trabalho, resultante de pesquisas desenvolvidas no âmbito do Programa Institucional de Iniciação Científica, subprojeto de Licenciatura em Letras - subárea Linguística, visa a analisar a representação da mulher e o papel que o feminino ocupam nas religiões cristãs, mais especificamente no discurso bíblico.

Para tal, utiliza-se da Análise do Discurso de corrente francesa, justamente por considerar que essa teoria dá suporte para compreender a Formação Ideológica (que em sua maioria, possui caráter de enaltecer ou desprestigiar a figura da mulher, por meio do discurso proferido). Trabalha-se, então, com uma teoria que, interessada no discurso e entendendo que "as relações de linguagem são relações de sujeitos e de sentidos e seus efeitos são múltiplos e variados" (ORLANDI, 1999, p. 21), preocupa-se com o efeito de sentido entre interlocutores.

Esta pesquisa é desenvolvida na Universidade Estadual do Norte do Paraná, campus de Cornélio Procópio (UENP/CCP), e está vinculada ao grupo de pesquisa Diálogos Linguísticos e Ensino: Saberes e Práticas (DIALE). 


\section{SEMINÁRIO DE PESQUISA EM CIÊNCIAS HUMANAS - SEPECH \\ Humanidades, Estado e desafios didático-científicos \\ Londrina, 27 a 29 de julho de 2016}

\section{DISCURSO E IDEOLOGIA}

Fiorin (1990) conceitua ideologia como o conjunto de ideias, de representações que servem para justificar e explicar a ordem social, as condições de vida do homem e as relações que ele mantém com os outros homens. $O$ autor considera, ainda, a ideologia como uma visão de mundo, ou seja, o ponto de vista de uma classe social a respeito da realidade, a maneira como uma classe ordena, justifica e explica a classe social. Pode-se deduzir, com isso, que há tantas visões de mundo numa dada formação social quantas forem as classes sociais.

No processo de interação, a ideologia ocupa um papel importante, pois mantém uma estreita relação com os valores dos indivíduos pertencentes a um determinado grupo social. Compreende a participação dos sujeitos nos acontecimentos e suas relações com os outros e com as coisas que os circundam. Essa forma de relacionamento denota a visão que se tem do mundo e traduz, portanto, a ideologia que conduz e orienta o sujeito para certas ações ou dizeres decorrentes de um conjunto de valores, ideias e procedimentos de concepções de natureza intelectual, política, religiosa, entre outras.

Cada indivíduo pode assumir mais de uma ideologia em um dado momento ou situação. Assim, uma mulher, por exemplo, que já pertence obviamente, ao grupo das mulheres, também pode pertencer a outros grupos como o das brasileiras, negras, mães, advogadas, enfim, várias identidades que interferem nas escolhas e estratégias utilizadas na comunicação.

Na visão de Althusser (1985), não é no campo das ideias que as ideologias existem e, portanto, não é aí que se encontra seu interesse teórico. As ideologias têm existência "material", é nessa existência material que devem ser estudadas, e não enquanto ideias. Trata-se, desse modo, de estudar as ideologias como conjunto de práticas materiais necessárias à reprodução das relações de produção. $\mathrm{O}$ autor afirma que as relações de poder são marcadas por diferenças de classes: a dominante, que representa a minoria que detém o poder (donos dos meios de produção) e a classe dominada (trabalhadores que produzem). Há, pois, a hegemonia da classe majoritária.

Entendendo que a luta de classes gira sobre o Estado, o autor designa pelo nome de Aparelhos Ideológicos de Estado (AIE) um certo número de realidades que se representam sob forma de instituições distintas e especializadas: a escola, a Igreja, a família, o sistema político, os meios de comunicação de massa, entre outros. Porém, estes não se confundem com os Aparelhos Repressores de Estados (ARE), lembrando que, na teoria marxista, o Aparelho de Estado (AE) compreende: o governo, a administração, o exército, a polícia, os tribunais, as prisões etc., que constituem o que Althusser chama de ARE. Repressivo indica que o aparelho repressivo de Estado em questão funciona pela violência, ou seja, são forças que fazem com que as leis sejam cumpridas.

Em suma, os ARE funcionam predominantemente por meio da repressão e secundariamente pela ideologia. Por isso, não há aparelho unicamente repressivo, já que temos como exemplos a Polícia e o Exército que funcionam também pela ideologia, tanto para garantir sua própria coesão e reprodução, como para divulgar os valores por eles propostos. Já os AIE funcionam de forma inversa, primeiro pela ideologia e segundo pela repressão, embora esta seja bastante atenuada, dissimulada ou mesmo simbólica. A Igreja, por exemplo, possui métodos que podem excluir, 


\section{SEMINÁRIO DE PESQUISA EM CIÊNCIAS HUMANAS - SEPECH \\ Humanidades, Estado e desafios didático-científicos \\ Londrina, 27 a 29 de julho de 2016}

selecionar ou aplicar sanções em suas ovelhas, assim como a Escola, a Família, entre outras instituições.

Brandão (1993), baseando-se nos postulados althusserianos, assevera que há três hipóteses para explicar o mecanismo de fixação teórica da ideologia:

a) "a ideologia representa a relação imaginária de indivíduos com suas reais condições de existência" (p. 22): nesse sentido, a ideologia é a maneira pela qual os homens vivem a sua relação com as condições reais de existência, relação esta, imaginária;

b) "a ideologia tem uma existência porque existe sempre num aparelho e na sua prática ou suas práticas" (p.23): a ideologia se materializa por meio de atos concretos, adotando um caráter moldador das ações. A prática só existe numa ideologia e por meio dela;

c) e "a ideologia interpela indivíduos como sujeitos" (p.23): a função de toda ideologia é constituir indivíduos concretos em sujeitos.

Mussalin (2001, p. 110) lembra que o discurso é tomado como:

(...) uma manifestação, uma materialização da ideologia decorrente do modo de organização dos modos de produção social. Sendo assim, o sujeito do discurso não poderia ser considerado como aquele que decide sobre os sentidos e as possibilidades enunciativas do próprio discurso, mas aquele que ocupa um lugar social e a partir dele se enuncia, sempre inserido no processo histórico que lhe permite determinadas inserções e não outras.

A ideologia em Ricoeur (apud BRANDÃO, 1993), faz uma interpretação do fenômeno ideológico partindo de uma análise em termos de classes sociais. Para ele, antes que se chegue às funções de dominação e justificação, que nos leva à aceitação sem crítica, à identificação de ideologia com noções de erro, mentira, ilusão, é preciso que sejam analisadas três instâncias:

a) Função Geral da Ideologia:

A ideologia exerce o papel de mediadora da integração social, na coesão do grupo por meio de cinco traços:

1) A ideologia perpetua um ato fundador inicial: não só executa o papel de difundir a convicção para além do círculo dos pais fundadores a fimm de convertê-la num credo de todo o grupo, como também o de perpetuar este ato fundador, o qual está ligado à necessidade, para um grupo social, de atribuir uma imagem de si mesmo, representando e encenando, no sentido teatral do termo.

2) A ideologia é dinâmica e motivadora: não é apenas um simples reflexo de uma formação social, a ideologia é também justificação (sua práxis é movida pelo desejo de demonstrar que o grupo que a professa tem razão de ser o que é) e projeto (dita as regras de um modo de vida).

3) Toda ideologia é simplificadora e esquemática: apresenta um caráter codificado para se dar uma visão de conjunto do grupo, da história e do mundo.

4) Uma ideologia é operatória e não-temática: em função do estatuto não-reflexivo e não-transparente da ideologia se filia à noção de dissimulação.

5) A ideologia é, poderíamos dizer, intolerante devido à inércia que parece caracterizá-la: considerando-se o novo como um perigo às bases estabelecidas pela 


\section{SEMINÁRIO DE PESQUISA EM CIÊNCIAS HUMANAS - SEPECH \\ Humanidades, Estado e desafios didático-científicos \\ Londrina, 27 a 29 de julho de 2016}

ideologia, esta opera um estreitamento das possibilidades de interpretação dos acontecimentos. Por conservar-se resistente às modificações, ela se fixa, enquanto os fatos se transformam.

b) Função de Dominação:

Está relacionada aos aspectos hierárquicos da organização social, que apresenta um sistema de autoridade que busca legitimar-se. Para que isso aconteça, é necessário que os indivíduos creiam nessa legitimidade. Como esta demanda mais crença do que os indivíduos podem dar, surge, então, a ideologia como sistema de justificador de dominação.

c) Função de Deformação:

A ideologia oscila entre dois polos: de um lado, tem-se a concepção de ideologia ligada à tradição marxista, que entende o fenômeno da ideologia como o mecanismo que leva ao mascaramento da realidade social, resultante na existência de um discurso ideológico que legitima o poder de uma classe social. Por outro lado, há o conceito de ideologia como uma visão de mundo de uma determinada comunidade social numa dada situação histórica. Essas duas concepções não se excluem, mas se cruzam, já que, partindo-se do princípio de que a ideologia, enquanto visão de mundo, apresenta-se como uma forma verdadeira de se pensar esse mundo, esta forma pode ser incompatível com a realidade. Faz-se, assim, um recorte da realidade, mesmo que por meio de manipulação, como pode ocorrer, por exemplo, com o discurso político, fazendo com que o real não se mostre na medida em que, intencionalmente, omitem-se, atenuam ou falseiam dados.

\section{A REPRESENTAÇÃo DA MULHER E O PAPEL DO FEMININO NO DISCURSO BÍBLICO}

Historicamente, a mulher é mantida como figura secundária, limitada, dependente do homem e marginalizada em diversos aspectos. A cultura patriarcal definiu à mulher um papel secundário nas diversas esferas sociais. Ao analisar a sua história, é possível perceber a origem desses estereótipos, que foram transmitidos de geração em geração, e que são predominantes em muitas religiões, inclusive nas religiões cristãs. Laffey traz a seguinte consideração:

O patriarcado, intimamente associado com hierarquia, é um modo de ordenar a realidade de forma que um grupo, no caso o sexo masculino, é tido como superior ao outro, o sexo feminino [...]. A opressão costuma ser sutil numa cultura patriarcal [...] A estereotipagem das funções dos sexos foi legitimada por muitas religiões e pela sociedade ocidental durante milênios. As mulheres que extrapolam o "seu lugar" e assumem posições normalmente reservada aos homens são "exceções". As exceções podem até ser louvadas pelos homens enquanto permanecem exceções. Mas quando há perigo de que a exceção se torne a norma, os homens se rebelam. Consequentemente, o patriarcado funciona melhor quando o sexo oprimido, o sexo 


\title{
XI SEMINÁRIO DE PESQUISA EM CIÊNCIAS HUMANAS - SEPECH \\ Humanidades, Estado e desafios didático-científicos \\ Londrina, 27 a 29 de julho de 2016
}

feminino, suporta o status quo e opta pela segurança que sua função oferece. (LAFFEY, 1994, p. 10).

A partir da consideração feita por Laffey, podemos perceber que a cultura do patriarcado impôs à mulher uma posição inferior ao homem diante da sociedade, de modo que se percebe uma ideologia machista, centrada no homem. Nesse modelo de sociedade, algumas mulheres podem até conseguir sair dessa posição de inferioridade e algumas das vezes até serem louvadas por isso, mas na maioria das vezes devem permanecer como inferiores e respeitarem as imposições feitas por esse modelo, o patriarcado. Apesar disso, existem algumas exceções, que são exceções justamente porque, se uma grande maioria de mulheres começar a ocupar lugares que nesse modelo eram reservados somente para os homens, elas serão oprimidas por diversos fatores também criados por esse modelo.

Silva (2002), em concordância com Laffey (1994), também traz uma definição do que é o patriarcado. Para a autora,

\begin{abstract}
A Teoria do Patriarcado considera que os homens são os primeiros responsáveis pela opressão feminina e que o patriarcado necessita da diferenciação sexual para se manter como um sistema de poder, fundamentado pela explicação de que homens e mulheres seriam em essência diferentes. (SILVA, 2002, p. 4).
\end{abstract}

Pautada nos conceitos de Silva (2002), Laffey (1994) e Simone (1949), buscamos entender as raízes das explorações/diferenças do homem sobre a mulher. A Teoria do patriarcado prevê que o sexo feminino é inferior/secundário pelo simples fato de ter em sua essência fatores biológicos que o diferenciam do sexo masculino, esse, por sua vez, é o detentor do poder nesse modelo de sociedade, o qual cria Aparelhos Ideológicos de Estado (AIE) e Aparelhos Repressores do Estado (ARE) para conservar essas diferenças/desigualdades.

Segundo Althusser (1985), os AIE são instâncias especializadas que agem na sociedade de forma não agressiva, mas ideológica que convencem os indivíduos a seguirem determinados padrões/regras impostas por um Estado/cultura. Já os ARE são instâncias que usam de força física (violência, agressividade) para conter um determinado individuo dentro de um padrão imposto por um Estado/cultura. São exemplos dos AIE as Igrejas, as escolas etc., e de ARE, a polícia, o exército, as prisões etc.

Assim, este trabalho visa, por meio da análise discursiva do discurso constituinte de religiões cristãs, ou seja, no discurso bíblico, analisar como se dá a representação da mulher e o papel do feminino nesse contexto, além de abordar fatores que determinam essas representações.

A religião cristã, por exemplo, defende a união de pessoas de sexo diferente para que haja a procriação: "Frutificai e multiplicai-vos; enchei a Terra e sujeitai-a" (GÊNESIS 1:28). Para o pensamento cristão, a família deve ser constituída pelo homem, que ocupa a posição de chefe da família, pai e marido. Dessa forma, o marido cristão, como pai e sacerdote da família, é seu instrutor, guia e provedor; e a mulher, como esposa e mãe da família cristã, é a responsável pela formação dos filhos. Assim, sua principal responsabilidade é instrui-los e educá-los de acordo com as instruções dadas na Palavra de Deus, a Bíblia. 


\title{
XI SEMINÁRIO DE PESQUISA EM CIÊNCIAS HUMANAS - SEPECH \\ Humanidades, Estado e desafios didático-científicos \\ Londrina, 27 a 29 de julho de 2016
}

Podemos, com isso, observar que o sistema patriarcal está arraigado na família cristã. A família molda os seus membros conforme o modelo patriarcal. É no âmbito familiar que os estereótipos, status e os papéis são, pela primeira vez, adotados, distribuídos e reproduzidos para a sociedade como modelos "corretos" de comportamento para cada um dos sexos.

Em consonância, deparamo-nos com Simone de Beauvoir (1949, p. 09), a qual contextualiza sobre o que é ser mulher e qual seu papel na sociedade. Para a autora,

\begin{abstract}
Ninguém nasce mulher: torna-se mulher. Nenhum destino psíquico, econômico define a forma que a fêmea humana assume no seio da sociedade; é o conjunto da civilização que elabora esse produto intermediário entre o macho e o castrado que qualificam de feminino.
\end{abstract}

Nessa citação, Beauvoir (1949) define que o papel que a mulher ocupa na sociedade não é definido por fatores (biológicos, psíquicos e econômicos), mas por um conjunto de regras imposto por um modelo de sociedade. Alguns desses modelos impõem à mulher uma socialização de inferioridade desde o nascimento e procura conservá-los ao longo da vida.

Como exemplo desse papel secundário que é imposto à mulher, principalmente dentro das religiões cristãs, podemos analisar o texto de Timóteo, em que Paulo faz uso de sua autoridade apostólica e ordena: "A mulher aprenda em silêncio, com toda submissão. E não permito que a mulher ensine, nem que exerça autoridade sobre $o$ marido; esteja, porém, em silêncio" (1TIMÓTEO, 2:11-12). Ou seja, o poder divino (oferecido a Paulo por Deus - o poderoso, imortal, onipotente, onipresente, onisciente, infalível) é sustentado pela desigualdade de papéis e de lugares entre homens e mulheres em vários grupos sociais.

Assim, notamos que, nesse discurso, a intenção é a de que a interação seja estabelecida de forma a conter a reversibilidade (ORLANDI, 1996), ou seja, congelar tanto o locutor quanto o ouvinte no lugar que lhe é de direito e dever (ORLANDI, 1996), e cujo sentido fica aprisionado pelo próprio dizer: único e inquestionável. Nesse sentido a reversibilidade trata-se de a Bíblia conter um discurso professado por uma autoridade/divindade (Deus) que não pode ser questionada ou desmistificada, tornando o ouvinte um ser assujeitado que não pode interagir nesse discurso, deve somente ouvilo e tê-lo como verdade única.

No discurso religioso, a mulher é oprimida pela sociedade patriarcal e assujeitada ainda mais à opressão, a qual, nesse caso, vem de um poder ainda mais superior (poder de Deus), determinando a ela papéis secundários, de inferioridade, de submissão perante o sexo masculino, conforme podemos observar neste versículo:

Mulheres, sujeitem-se a seus maridos, como ao Senhor, pois o marido
é o cabeça da mulher, como também Cristo é o cabeça da igreja, que
é o seu corpo, do qual ele é o Salvador. Assim como a igreja está
sujeita a Cristo, também as mulheres estejam em tudo sujeitas a seus
maridos. (EFÉSIOS, 5: 22-24).

Nesse trecho da Bíblia, podemos perceber a comparação entre mulher e a igreja, uma sujeita ao marido e outra a Deus. A mulher deve obedecer não somente às leis de Deus, mas também aos comandos do marido, sendo colocada, dessa forma, como 


\section{SEMINÁRIO DE PESQUISA EM CIÊNCIAS HUMANAS - SEPECH \\ Humanidades, Estado e desafios didático-científicos \\ Londrina, 27 a 29 de julho de 2016}

inferior a ele. $\mathrm{O}$ marido é posto como cabeça e a mulher como corpo, ou seja, o marido dá comandos e a mulher, como um bom corpo, corresponde apenas, sem questioná-los ou negá-los.

"A linguagem religiosa está revestida de autoridade daquele que representa a Deus, mas que não é Ele" (ORLANDI, 1996). Essa característica é nomeada por Orlandi (1996) como ilusão da reversibilidade. Dessa maneira, o discurso proferido por um líder religioso, representante de Deus aqui na Terra, incentiva a reprodução de estereótipos, conduzindo a figura feminina à submissão, fortalecendo a ideia de que a mulher é hierarquicamente inferior ao homem, cuja única utilidade é ser reprodutora da espécie: "Entretanto, a mulher será salva dando à luz filhos - se elas permanecerem na fé, no amor e na santidade, com bom senso" (1TIMÓTEO, 2:15), estando sempre dependente sexual e socialmente da figura masculina. Assim, vejamos:

[...] a serem prudentes e puras, a estarem ocupadas em casa, e a serem bondosas e sujeitas a seus próprios maridos, a fim de que a palavra de Deus não seja difamada. (TITO, 2:5).

Destarte, nesse texto bíblico (TITO 2:5), a mulher é assujeitada a um papel que não seja de sua própria personalidade, mas imposto pela voz autoritária que representa a voz divina em que a mulher deve ser pura, bondosa, deve se ocupar com as tarefas domésticas e ser sempre ser submissa ao marido.

Ádmite-se unanimemente que a conquista de um marido - em certos casos, de um protetor - é para ela o mais importante dos empreendimentos. No homem encarna-se a seus olhos o Outro, como este para o homem se encarna nela; mas esse Outro apresenta-se a êle como o essencial e ela se apreende perante êle como o inessencial. Ela se libertará do lar paterno, do domínio materno e abrirá o futuro para si, não através de uma conquista ativa e sim entregando-se, passiva e dócil, nas mãos de um novo senhor. (BEAUVOIR, 1942, p.67).

Com a citação de Beauvoir, percebe-se que ter um marido é o mais importante investimento na vida da mulher, a qual o vê como uma aquisição de liberdade, em que poderá ter e defender seus próprios interesses sem a mediação e intervenção do pai, porém faz isso de forma a se tornar passiva ao marido e deixando seus ideais para defender os dele.

O encargo que lhe impõe a sociedade é considerado como um serviço prestado ao esposo: em consequência deve êle à esposa presentes ou um dote e compromete-se a mantê-la; é por seu intermédio que a sociedade se desobriga em relação à mulher que lhe entrega. Os direitos que a esposa adquire cumprindo seus deveres traduzem-se por obrigações a que o homem se submete. (BEAUVOIR,1942,p.167).

A sociedade é que impõe a mulher que ela seja submissa ao marido e uma vez casada se dispõe a prestar serviços a ele, ou seja, o homem é submisso à sociedade que lhe impõe deveres a serem cumpridos, e ele incube a mulher de ajudá-lo nessas obrigações, isso em troca de proteção, subsistência e presentes. Percebe-se, assim, uma 


\section{SEMINÁRIO DE PESQUISA EM CIÊNCIAS HUMANAS - SEPECH \\ Humanidades, Estado e desafios didático-científicos \\ Londrina, 27 a 29 de julho de 2016}

ideologia machista que permeia a representação da mulher e do papel do feminino no corpus analisado.

\section{CONSIDERAÇÕES FINAIS}

$\mathrm{Na}$ contemporaneidade, a sociedade exige que a mulher aceite o papel que lhe foi estipulado pela cultura do patriarcado, especialmente dentro da religião e tudo que tange a questões das crenças cristãs. Dessa forma, tentou-se, por meio de conceitos da Análise do Discurso, investigar desdobramentos que não dizem respeito somente sobre às práticas discursivas, mas também acerca das estruturas, estereótipos, conceitos, concepções ideológicas, religiosas que partem das práticas discursivas e seguem até a questão da representação da mulher e o papel do feminino dentro da religião cristã.

Assim, houve a intenção de esclarecer que, no discurso bíblico, a mulher está sempre dependente, submissa ao homem, e analisar a questão da representação da figura feminina associada (ou dentro da religião), e reconhecer/encarrar a realidade de submissão e desigualdade imposta pela cultura patriarcal.

Por meio da $\mathrm{AD}$, podemos observar/revelar a função do discurso na (re)produção da dominação social. A discussão a respeito da representação da mulher, neste trabalho, conduziu a uma abordagem por meio da Análise do Discurso que visou a romper com o patriarcado e com uma ideologia machista e, consequentemente, acabar com a desvalorização da mulher (que é pautada apenas por quesito do sexo, ou seja, por ter nascido mulher) dentro e fora dos limites da igreja. Melhorar a relação da valorização da mulher é melhorar de forma significativa a sociedade na qual estamos inseridos.

\section{REFERÊNCIAS}

ALTHUSSER, L. Aparelhos ideológicos de estado. Rio de Janeiro: $6^{\text {a }}$ ed. Graal, 1985. AUTHIER-REVUZ, J. Palavras incertas: as não-coincidências do dizer. Campinas: Pontes, 1998.

BEAUVOIR, S. de. Le deuuxième sexe. Paris, Gallimard, 1942.

BRANDÃO, H. N. Introdução à Análise do Discurso. 2. ed. Campinas: Editora da Unicamp, 1993.

FIORIN, J. L. Linguagem e ideologia. São Paulo. Ática, 1990.

LAFFEY, A. Introdução ao Antigo Testamento: perspectiva feminista. São Paulo: Paulus, 1994.

ORLANDI, E. Análise do discurso: princípios e procedimentos. Campinas: Ed. Pontes, 1999. 


\section{SEMINÁRIO DE PESQUISA EM CIÊNCIAS HUMANAS - SEPECH \\ Humanidades, Estado e desafios didático-científicos \\ Londrina, 27 a 29 de julho de 2016}

ORLANDI, E. P. O discurso religioso. In: A linguagem e seu funcionamento: as formas do discurso. 4. ed. Campinas, SP: Pontes, 1996. p.239-262.

SILVA, E. R. da. Feminismo radical: pensamento e movimento. Travessias, Educação, Cultura, Linguagem e Arte, Fortaleza, UFC, ed. 4, p. 01-15, 2002.

VOGT, C. Linguagem, pragmática e ideologia. São Paulo: Hucitec, 1989 